\title{
Globalización en Copiapó, Chile: aplicación de un modelo económico orientado a las exportaciones frutícolas.
}

Luz Alicia Cárdenas Jirón

Pablo Carrasco Milla

Filiación: Luz Alicia Cárdenas Jirón, MSc. Urban Development Planning. Profesora Asociada, Departamento de Urbanismo, Facultad de Arquitectura y Urbanismo, Universidad de Chile. Dirección: Casilla 3387, Santiago, Chile.

E Mail: Icardena@uchile.cl

Pablo Carrasco Milla, tesista Carrera Arquitectura, Facultad de Arquitectura y Urbanismo, Universidad de Chile.

\section{Resumen}

Este artículo da cuenta de una investigación que tiene por objeto evaluar cambios en la estructura urbana de ciudades de rango medio insertas en la economía global. Se escoge Copiapó por el espectacular crecimiento económico derivado del modelo orientado a las exportaciones frutícolas de uva de mesa, que constituyó la nueva base económica de una región tradicionalmente minera y semiárida del norte chileno. Luego de 30 años de aplicación del modelo se analizan los cambios en la ciudad y el territorio empleando referentes conceptuales propios del proceso tales como: los "servicios de producción avanzada" y los "artefactos de globalización".

\footnotetext{
Abstract:

The current paper disseminates research results. Its purpose was to evaluate changes in urban structure of medium-size cities which are involved in the global economy. Copiapó was selected because of its spectacular economic growth supported by grapes table export-oriented model. Then grapes table become a new economic base in a traditional mining and semi-arid region in the Chilean northern. Changes on cities and territory were examined after 30 years of applying model. Conceptual references from globalization framework were applied such as "advanced production services" and "globalization artifacts".

Palabras claves: GLOBALIZACIÓN; SERVICIOS DE PRODUCCIÓN AVANZADA; ARQUITECTURA DEL PACKING; MODELO ORIENTADO A EXPORTACIÓN; ARTEFACTOS DE LA GLOBALIZACIÓN.
}

Key words: GLOBALISATION; ADVANCED PRODUCTION SERVICES; PACKING ARCHITECTURE; EXPORT-ORIENTED MODEL; GLOBALISATION ARTIFACT. 


\section{I ntroducción}

Globalización es un proceso de orden económico que ha re estructurado la economía mundial desde la década de los ochenta hasta hoy, produciendo, entre otros, repercusiones espaciales y territoriales en el globo terráqueo. Las tecnologías de la información han posibilitado la existencia de redes de comunicación que viabilizan transacciones financieras en tiempo real, acercando digitalmente territorios, otrora alejados geográficamente. En ese contexto, algunas ciudades del mundo han propuesto modelos de desarrollo orientados hacia las exportaciones, como una manera de insertar la economía local en la global. El modelo de economía política llamada Ajuste Estructural promueve una forma de capitalismo que traspasa las fronteras nacionales y se posiciona internacionalmente mediante redes de flujo de capital, lo que se conoce como la globalización, (Sassen, 1990)

Planificaciones estratégicas que identifican ventajas comparativas del territorio nacional fueron emprendidas por algunos países del mundo entero para hacer crecer sus economías que se encontraban en franco deterioro y estancamiento en período post industrial en las década del 70. Chile fue uno de estos países que adoptó el nuevo modelo de desarrollo orientado a las exportaciones, como una forma de generar crecimiento económico, competitividad e inserción en la economía global. (De Castro, 1992). Es así como en los ochenta promueve desde el aparato estatal y el sector privado el desarrolllo de nuevos nichos de mercado en sectores no tradicionales: frutícola, forestal y pesquero, (Gwyne, 1993). Se postula a modo de hipótesis que las ciudades de rango medio, asociadas a esta nueva base económica exportadora, jugaron un rol protagónico en este proceso de reestructuración de la economía nacional. Repercusiones sociales, económicas y ambientales, se han documentado en diversas publicaciones, (Gwynne, 1997; Figueroa, 1993; Sunkel, 1996). Sin embargo, aspectos propiamente urbanísticos de la "nueva" organización espacial en el sistema urbano y territorial, ha sido menos estudiada, en particular las ciudades de rango medio chilenas.

Estudiar por ejemplo: ¿Cuáles fueron los cambios en los usos de suelo de las ciudades de rango medio?; ¿Cuál es la nueva configuración espacial y territorial de estos sistemas urbano-rural?; ¿Cómo la población se adapto a estos cambios?; ¿Cómo reacciona el mercado inmobiliario?. La respuesta a estas interrogantes es el propósito que intenta analizar este articulo, tomando como caso de estudio, Copiapó, la ciudad capital del primer valle transversal que se incorporó a globalización mediante la exportación de uva chilena a mercados internacionales.

Las exportaciones de fruta chilena a otros continentes ha desencadenado una serie de transformaciones en el territorio, que abarca el sistema urbano rural, vale decir el conjunto de centros poblados del valle en producción y la infraestructura de comunicación y transporte. Las ciudades y sus entornos naturales han experimentado cambios significativos que modifican el paisaje natural y urbano. La re composición de usos de suelo en la ciudad principal de estos sistemas urbanos esta reflejando un cambio en la estructura de la economía local. La emergencia de "servicios de producción avanzada", propios de una economía en globalización, se han localizado en ciudades chilenas de tamaño medio.

La constatación y cuantificación de estas transformaciones urbanísticas es la materia a tratar en el presente estudio, tomando en consideración los referentes teóricos conceptuales del proceso de globalización y de economía urbana. Por tanto, el objetivo de este artículo es mostrar las transformaciones en la estructura de usos de suelo, demografía, y las repercusiones espacialesterritoriales derivadas del modelo orientado a las exportaciones frutícolas, luego de más de tres décadas de aplicación. Y como objetivo específico se pretende identificar la arquitectura emergente, dado que es también un reflejo de estos cambios en el espacio urbano y territorial del valle de Copiapó.

Las técnicas de análisis empleadas son la observación in situ, entrevistas con actores sociales, institucionales y económicos del desarrollo urbano, tales como vecinos de los barrios, Director de Obra, Asesor Urbanista, Directora Desarrollo Social, Director de Rentas Municipales, arquitectos 
independientes y arquitectos de la Cámara Chilena de la Construcción en Copiapó. Además, estudio de catastros de usos de suelo, análisis de tendencias de datos estadísticos demográficos del INE en una serie temporal 1982, 1992, y 2002, estadísticos financieros del Banco Central y estadísticos del mercado inmobiliario de la Cámara Chilena de la Construcción.

El artículo analiza en primer lugar el contexto en el cual se origina el modelo orientado a las exportaciones. En segundo lugar analiza los conceptos claves para entender el proceso de localización de actividades urbanas, la teoría de base económica, cadenas exportadoras, globalización y las evidencias mediante los nuevos términos acuñados tales como "servicios de producción avanzada" y "artefactos de la globalización". En tercer lugar aporta antecedentes de Copiapó; demográficos, económicos y urbanísticos para posteriormente realizar un análisis e interpretación de los mismos. Finalmente arriba a conclusiones del proceso observado.

\section{Regionalización e implementación de un modelo orientado a las exportaciones}

La regionalización y descentralización político administrativo del territorio chileno iniciada a mediados de los setenta en Chile, buscaba otorgar autonomía y desarrollo a las regiones, para lo cual dividió el territorio nacional en 13 regiones y adoptó un modelo orientado a las exportaciones. El objetivo estratégico era insertar la economía local en la economía global. Así, planificó la búsqueda de nuevos nichos de mercado asociados a la explotación y exportación de recursos naturales en las regiones. Un modelo de desarrollo que permitiera reactivar la economía nacional a través de su inserción en la economía global a través de mecanismos de competitividad y liberalización del mercado. Para ello Chile adopta un modelo de desarrollo basado en las exportaciones de productos no tradicionales.

Figueroa afirma que el cobre era el producto principal de las exportaciones chilenas, hasta el primer quinquenio de los setenta, el cual fue perdiendo importancia relativa dada la aparición de nuevos sectores de exportación. En la tabla $\mathrm{N}^{\circ} 1$ se observa esta declinación en el período observado, (Figueroa, 1999).

\begin{tabular}{|c|c|c|}
\hline \multicolumn{3}{|c|}{$\begin{array}{c}{\text { Tabla } N^{\circ} 1} \\
\text { Chile: exportaciones mineras } \\
1975-1994\end{array}$} \\
\hline Período & Tasa de crecimiento (1) & \% Exportaciones Totales \\
\hline $1975-1980$ & 6,5 & 63,9 \\
\hline $1980-1985$ & 5,4 & 59,4 \\
\hline $1985-1990$ & 2,2 & 57,1 \\
\hline $1990-1994$ & 5,3 & 47,4 \\
\hline $1975-1994$ & 4,9 & 57,2 \\
\hline
\end{tabular}

La planificación estratégica desde el aparato estatal en conjunto con la participación del sector privado identificaron tres sectores no tradicionales de exportación: el sector agrícola, el sector pesquero y el sector forestal, (Gwynne, op cit.) Esto permitió diversificar el sector exportador y reducir la alta dependencia de las exportaciones del cobre, el cual representaba cerca de un $70 \%$ de las exportaciones al comienzo de los setenta, y se reduce a un $47,4 \%$ a mediados de los noventa. En cambio, las exportaciones de los sectores agrícolas, pesqueros y forestales representaban un 43, 3\% y las exportaciones industriales un 12,8 \%. (Figueroa et al., 1996). Según el mismo autor el dinamismo del sector exportador en dos décadas fue extraordinario, lo cual se observa en las tasas de crecimiento de las exportaciones de recursos naturales indicados en la tabla $\mathrm{N}^{\circ} 2$. Así, se inicia un proceso productivo intensivo en recursos naturales, localizándose 
en aquellas regiones que presentaban ventajas comparativas, básicamente proveer el insumo a exportar.

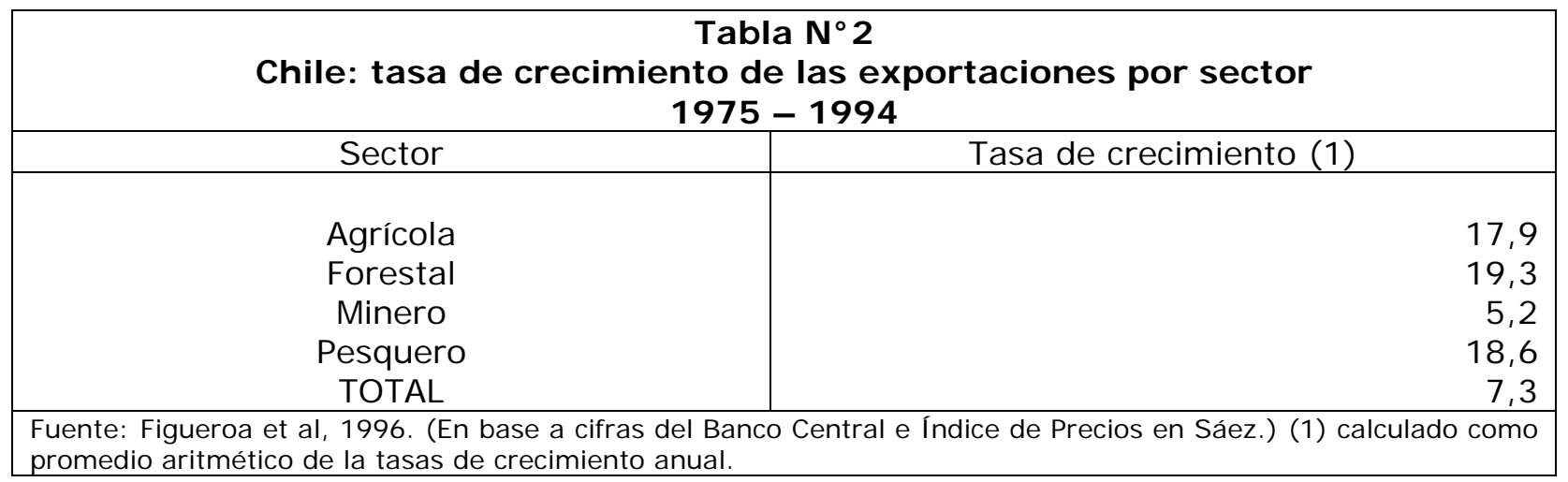

Las exportaciones del sector agropecuario, silvícola y pesquero muestran un crecimiento sostenido en los últimos veinte 20 años del período exportador, según se indica en la Tablas 3 A y 3 B. El período comprendido entre 1990 y 2007 las exportaciones han crecido más del triple, desde US\$994,5 millones de dólares hasta US\$3.187 millones. La composición de las exportaciones de este sector indica que el subsector frutícola lidera el crecimiento y en particular, la uva de mesa. Ver Fig. 1.A y Fig.1.B

\begin{tabular}{|c|c|c|c|c|c|c|c|c|c|c|}
\hline \multicolumn{11}{|c|}{$\begin{array}{c}\operatorname{Tabla~N}^{\circ} 3 \text {-A } \\
\text { Chile: evolución de las exportaciones frutícolas (US\$ millones) } \\
1990-1999\end{array}$} \\
\hline SECTOR & 1990 & 1991 & 1992 & 1993 & 1994 & 1995 & 1996 & 1997 & 1998 & 1999 \\
\hline $\begin{array}{l}\text { Agropecuario } \\
\text { Silvícola y } \\
\text { Pesquero }\end{array}$ & 994,5 & 1213,9 & 1252,8 & 1166,0 & 1298,1 & 1566,3 & 1594,1 & 1629,0 & 1576,1 & 1529,5 \\
\hline $\begin{array}{l}\text { Sector } \\
\text { frutícola }\end{array}$ & 756,7 & 984,1 & 1005,0 & 869,5 & 975,9 & 1172,4 & 1266,1 & 1283,6 & 1261,3 & 1211,5 \\
\hline Uva & 383,4 & 487,9 & 438,5 & 460,1 & 475,5 & 531,5 & 553,3 & 626,6 & 567,3 & 543,9 \\
\hline
\end{tabular}

\begin{tabular}{|c|c|c|c|c|c|c|c|c|}
\hline \multicolumn{9}{|c|}{$\begin{array}{c}\text { Tabla } N^{\circ} 3 \text {-B } \\
\text { Chile: evolución de las exportaciones frutícolas (US\$ millones) } \\
2000-2007\end{array}$} \\
\hline SECTOR & 2000 & 2001 & 2002 & 2003 & 2004 & 2005 & 2006 & 2007 \\
\hline $\begin{array}{l}\text { Agropecuario, } \\
\text { Silvícola y } \\
\text { Pesquero }\end{array}$ & 1693,0 & 1727,2 & 1794,2 & 2127,5 & 2372,5 & 2523,6 & 2738,8 & 3187,4 \\
\hline Sector frutícola & 1368,2 & 1433,4 & 1521,9 & 1826,9 & 2037,9 & 2176,9 & 2375,5 & 2772,4 \\
\hline Uva & 677,3 & 661,7 & 681,7 & 711,4 & 875,0 & 931,1 & 975,0 & 1008,4 \\
\hline
\end{tabular}




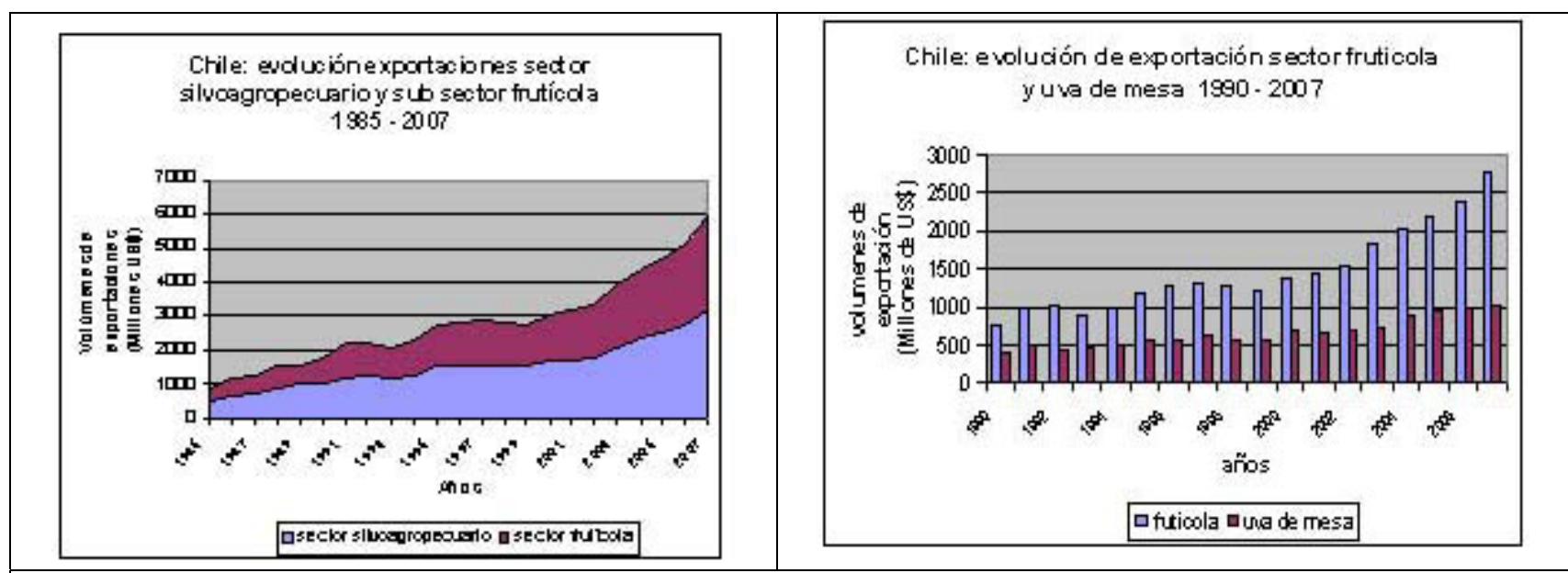

Figs.1.A y 1B: Chile: evolución de las exportaciones agropecuario, frutícola y uva de mesa. Fuente: Banco Central. Elaboración: Cárdenas 2008.

De lo anterior, se deduce que en un período de más de 30 años, entre 1975 a 2007, se ha sostenido el crecimiento de las exportaciones de uva de mesa, siendo el valle de Copiapó uno de los primeros proveedores de uva del territorio nacional. Esta condición es favorecida por características geográficas y climáticas del valle, tales como las altas temperaturas, intensa radiación solar, gran número de días de insolación, la orientación Norte Sur de los valles; la calidad de los suelos, aprovechando la potencialidad de los espacios semiáridos. (Fig.2). Esta situación sumada a la modernización tecnológica para el regadío, permitieron la maduración de la uva antes que los competidores en el hemisferio norte, lo cual facilitaba la penetración en el mercado internacional. De esta manera, ventajas comparativas de los diferentes espacios se transforman en ventajas competitivas en un contexto de globalización. (Luzón, 1997). Chile logró insertarse pionero a nivel latinoamericano registrando el mayor crecimiento de esas exportaciones y llegó a ser el primer exportador de fruta del hemisferio sur, (Gwynne, 1997).

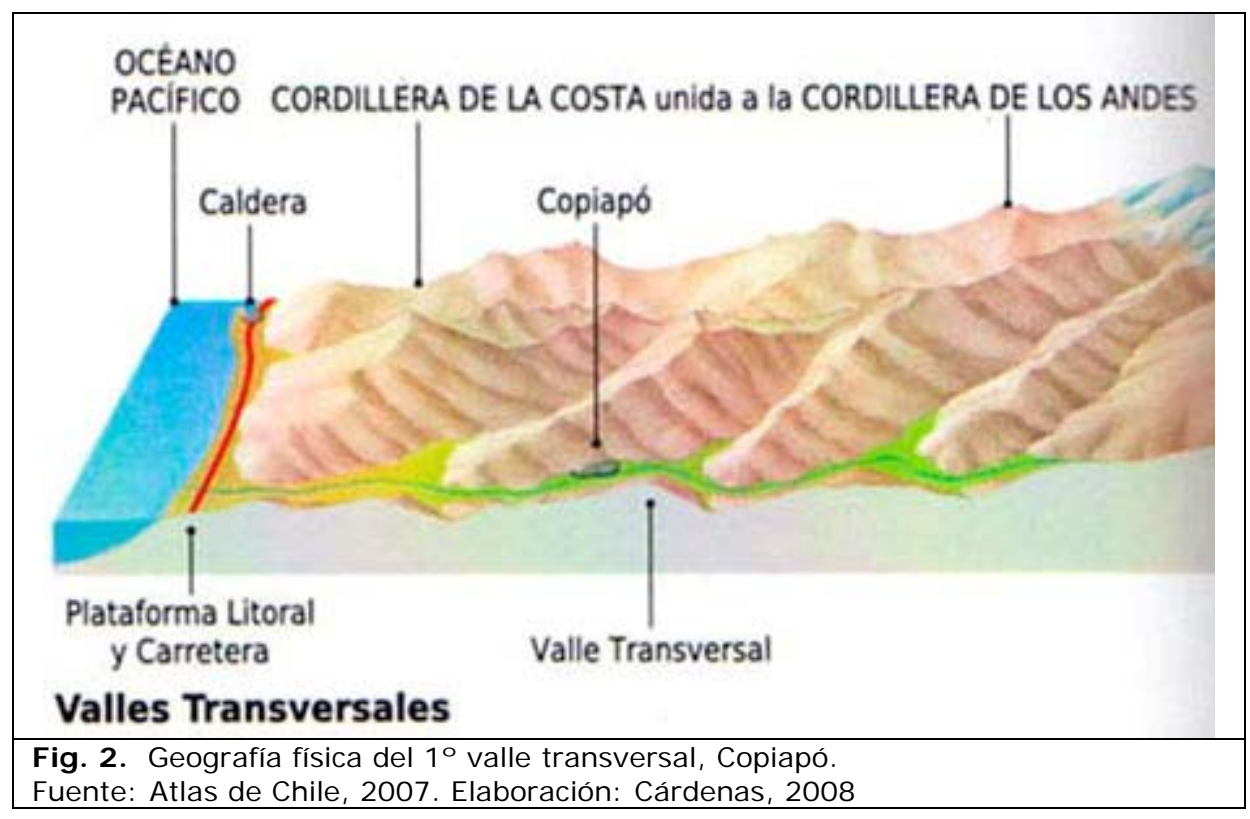

En virtud de ello, se ha intentado constatar las transformaciones en la estructura urbana, en particular en los servicios de producción avanzada y los artefactos de la globalización. 


\section{Globalización, servicios de producción avanzada y artefactos de globalización.}

La estructura y funcionamiento de la economía urbana es fundamental para realizar un análisis de los usos de suelo y de vitalidad en las ciudades. Por economía urbana se entenderá al sistema de producción, distribución y consumo que abarcan la totalidad de las actividades productivas dentro de un centro urbano y su hinterland. Estas actividades dependen fuertemente de las facilidades y servicios disponibles en la ciudad. Las funciones productivas y de distribución de bienes y servicios condicionan la cantidad de suelo requerida, así una economía en expansión requiere suelo para su localización, en cambio una economía en declinación libera suelo. Un clásico ejemplo lo constituyen el abandono de las áreas centrales e industriales - portuarias de ciudades inglesas, durante el periodo post industrial de los setenta, (Tallon, 2006). En esta misma línea, una actividad económica en crecimiento mantiene funciones productivas y de distribución que crean trabajos y oportunidades de empleo que a su vez atraen población dependiente de ese empleo. (Chapin, 1965). La población a su vez, requiere de viviendas para vivir en la ciudad con lo cual se activa un mercado inmobiliario que ofrezca viviendas, equipamiento y servicios para esa población.

Según Chapin, hay dos aproximaciones conceptuales al estudio de la economía urbana: una orientada regionalmente y la otra orientada localmente. Esta última, el centro urbano es el interés principal al mismo tiempo que sus relaciones exteriores con otros centros urbanos. Se conoce como la teoría de "base económica", en la cual se estiman los bienes y servicios de la actividad productiva que se consumen interna y externamente al centro urbano. Esta teoría distingue dos clases de actividades productivas: (i) las actividades "básicas" que producen y distribuyen bienes y servicios para exportar a empresas e individuos fuera del área localizada; y (ii) las actividades "no básicas" o de servicios, los cuales son consumidos dentro del área localizada.

A partir de este planteamiento, la actividad productiva básica traería nuevo dinero hacia la comunidad, en cambio la actividad no básica, simplemente recircula el dinero que ya existe en el área localizada. Por tanto, la actividad básica es clave para el fortalecimiento y expansión de la economía local, pues no solamente inyecta nuevos recursos económicos sino también promueve el crecimiento en actividades de servicios para la actividad básica y con ello la economía en su totalidad.

Se ha escogido la teoría de base económica para el análisis del sistema urbano y territorial de Copiapó, porque se ajusta al fenómeno observado en las ultimas tres décadas, derivado de una política económica orientada estratégicamente a las exportaciones. En este sentido, actividades productivas básicas que están localizadas fuera de la ciudad de Copiapó, extractivas o primarias, pero dependen fuertemente de los servicios y de población que se encuentra localizada en la ciudad de Copiapó y en otras ciudades. Estas actividades productivas básicas son destinadas para el consumo exterior, lo cual obliga a exportar a otros centros urbanos, principalmente fuera del país.

Las funciones de producción y distribución, consideradas de servicio o no básicas, se localizan en los centros urbanos de Copiapó, Caldera. Los centros urbanos del consumo se localizan fuera del territorio nacional, en ciudades norteamericanas, europeas y asiáticas según muestran los bloques económicos de destino en la Fig.3. En esta figura se observa los siguientes porcentajes para Enero del 2008: NAFTA con un $11.4 \%$ de los valores de exportación expresados en millones de dólares (US\$), MERCOSUR con un 3\%, UNION EUROPEA con un 7\%, APEC con un $21.4 \%$, PACTO ANDINO con un $0,3 \%$ y otros destinos, entre los cuales se encuentra China, con un $56.9 \%$ respectivamente. 


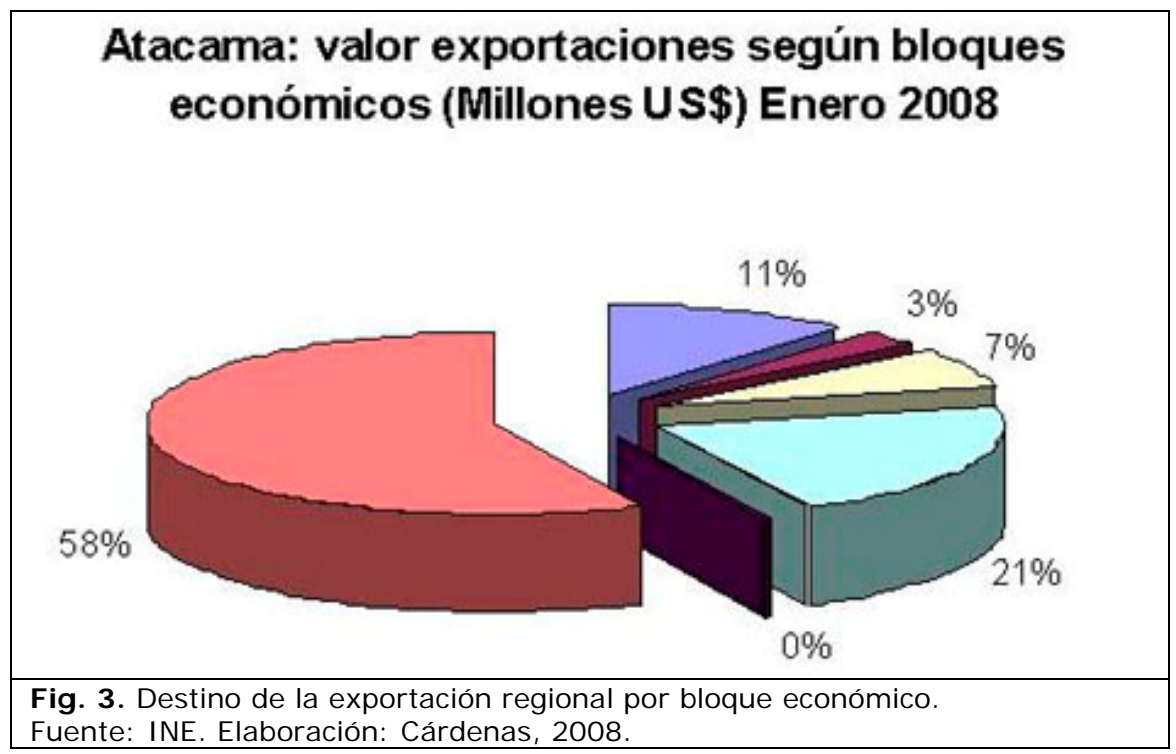

Gwynne describe sinópticamente la cadena exportadora frutícola reconociendo fases del proceso: la producción, la distribución, la comercialización del producto y el consumo, (Gwynne, 1999). Este autor afirma que las fases forman parte de una economía global encadenada, la cual se caracteriza por localizarse en distintos territorios del mundo y en diferentes escalas de resolución geográfica. De la global a la local, nacional a regional. Así, por ejemplo, la producción de fruta se localiza en países en vías de desarrollo y el consumo se localiza en países desarrollados.

Esta nueva forma de funcionamiento y organización espacial esta reflejando el contexto de globalización, el cual según Sassen consiste en un nuevo orden económico y social global basado en la formación de un capital global, en breve, ella lo sintetiza como una internacionalización de la industria financiera, (Sassen 1991) En términos de su organización espacial, la globalización presenta una nueva geografía aparentemente dual: una dispersión espacial de funciones productivas y al mismo tiempo una concentración de las funciones de comando y control en algunas ciudades, las cuales juegan un rol protagónico. La dispersión territorial es integrada mediante redes y facilitada por las tecnologías de las comunicaciones. Las ciudades que forman parte de la globalización proveen los llamados "servicios de producción avanzada" e innovaciones financieras para mantener los flujos de capital. Corresponde a un conjunto de empresas que producen servicios.

Incluyen servicios financieros, legales y de gestión entre los cuales se encuentran las aseguradoras, los bancos, los inmobiliarios, legales y contables, asociaciones profesionales en general. En particular, la innovación, diseño, administración, tecnologías de producción, manutención, transporte, comunicaciones, distribución mayorista, publicidad, servicios de limpieza para empresas, seguridad y almacenaje, (Sassen, 2001). La magnitud y diversidad de estos servicios dependen de la jerarquía de las ciudades globales.

Para De Mattos, los efectos del proceso de globalización se abordan desde tres perspectivas, cambios en la base económica, cambios en la estructura social, y cambios en la morfología urbana. (De Mattos, 1999). Desde la perspectiva de la arquitectura, el artículo se centra en los efectos físico - territoriales de la globalización. Entre ellos emergen las obras que sostienen las actividades económicas asociadas a los flujos de capital y transporte de bienes y personas. Estas obras urbanas contribuirían a impulsar el crecimiento, lo que el autor denomina "artefactos de globalización". Entre ellas se distinguen los edificios para actividades empresariales, comerciales, residenciales, edificios con equipamiento avanzado o "inteligentes", edificios con alto estándar en educación y salud, sistemas de comunicaciones y transporte modernos, infraestructura comercial diversificada y especializada, aeropuertos, etc. 


\section{Estructura espacial urbana de Copiapó en el sistema territorial del valle de Copiapó.}

Cabe mencionar que el sistema territorial urbano de Copiapó ha tenido históricamente como base económica la minería, la cual ha determinado el crecimiento físico y demográfico en el valle y principalmente en la ciudad de Copiapó. Sin embargo, la actividad minera ha presentado fluctuaciones dependiendo del descubrimiento del metal y su valor en los mercados internacionales, hechos que se reflejan en la dinámica demográfica y urbana, (Carrasco, 2008). Es importante destacar el trabajo de Carrasco quien analiza la ciudad de Copiapó en forma retrospectiva y prospectiva asociando su crecimiento al cambio en el valor internacional del metal y proyectando demandas futuras para la ciudad. Copiapó viene del vocablo "Copayapu" que significa Copa de Oro, lo cual evidencia también su origen ligado al metal precioso.

La actividad exportadora de la uva de mesa se inicia a fines de los setenta, posterior al proceso de regionalización chilena en 1976, se consolida en la década de los ochenta. Este artículo focalizará en aquellas transformaciones urbanas y territoriales del periodo histórico correspondiente a la generación y expansión agroindustrial de la uva de exportación. No obstante lo anterior, para entender la estructura espacial urbana de Copiapó y el sistema territorial del valle, se presenta en forma escueta antecedentes históricos, demográficos y económicos generales.

Copiapó ha experimentado a través de la historia, el impacto de los altibajos de la economía local. Aprovechando en determinados momentos el auge minero para traer servicios y equipamiento a la ciudad, logrando los mayores avances de la época y con altas tasas en su edificación. En otros ha logrado superar prolongados períodos de decadencia y abandono, gracias al desarrollo de la agricultura de exportación, la uva de mesa. Estos marcados ciclos económicos han quedado plasmados en la ciudad, dando forma a una irregular estructura urbana y espacial.

Copiapó, con origen anterior a su fundación en el período colonial -donde ya era un asentamiento productivo minero y de servicios agrícolas para la zona- otrora lugar de paso obligado para quienes vivían y trabajaban cerca del desierto; experimenta un primer período de auge a partir de 1830 y durante el primer tercio del Chile republicano gracias a la explotación del mineral de Plata "Chañarcillo"; lo que significó la primera gran expansión de la ciudad, con avances notables, tales como la llegada del primer ferrocarril al país y la fundación de la primera institución de formación superior del norte de Chile, La Escuela de Minas de Copiapó.

Sin embargo, al agotarse los grandes yacimientos de ese período, vendría una sostenida depresión apoyada en la alta migración de la población local, especializada en la minería. Esta población se movilizó en busca de oportunidades en las salitreras de los nuevos territorios agregados tras la Guerra del Pacifico.

No fue hasta mediados del siglo pasado que esta actividad económica -la minería- marca un repunte, con la apertura de nuevos yacimientos y plantas ligadas a las nuevas y altas demandas internacionales por cobre y hierro, que devuelven la vida y sustento a la ciudad. Desde entonces, han sido nuevamente, procesos basados principalmente en la minería, así como también en la agricultura tecnificada, servicios y el incipiente turismo, entre otros, los que han posicionado a Copiapó como lugar estratégico entre todos los núcleos urbanos y productivos de la región.

Cuatro son las acciones que propician este cambio en la economía y producción regional. En primer lugar, la creación de la planta de fundición Paipote (1953), dedicada a potenciar las actividades de la pequeña y mediana minería local. En segundo lugar, la puesta en marcha del embalse Lautaro (1930), que permite regar gran parte del Valle del Río Copiapó y, a futuro, potenciar la modesta agricultura de hortalizas para el consumo local. En tercer lugar, pero mas importante, es el cambio en la administración geopolítica, del territorio, en el proceso de regionalización, (1976) en que se crea la región de Atacama, y se pone a la cabeza a la ciudad de Copiapó. Esta nueva condición le entrega además una importante dotación de servicios y equipamiento asociado a las nuevas funciones. Como Hospital, intendencia y otros servicios 
asociados. En cuarto lugar, la aparición de la agroindustria de exportación, específicamente del cultivo de la uva de mesa (1980).

Estas dos últimas condiciones, permiten que la ciudad presente desde entonces, y sostenidamente, las tasas de crecimiento más altas de su historia. Pasando de los 50.000 habitantes en el 1970 a cerca de 175.000 habitantes estimados para el 2007. Concentrando en nuestros días más de la mitad de la población y vivienda de Atacama, en un interesante fenómeno de gravitación que ejerce la ciudad respecto del resto de las ciudades de Atacama. Y que se explica en gran parte, por su inmejorable localización respecto de los focos productivos y urbanos de la región, y de la infraestructura vial, comercial, de equipamiento y servicios que esta ciudad posee en la actualidad.

La curva demográfica de Copiapó, muestra cómo la ciudad ha vivido a lo largo de su historia marcado ciclos de auge y caída, ligados a los distintos procesos mineros del norte de Chile: oro colonial y fundacional, la plata republicana (1938 Chañarcillo), salitreras y desarrollo de la I y II regiones, y hierro y cobre a partir del 50, atrae nueva población. Sin embargo, a fines de los setenta e inicios de los ochenta se observa un crecimiento casi exponencial, alcanzando un peak que bordean los 250.000 habitantes en 1980 y luego otro peak de 320.000 habitantes en 1996. Fig. 4.

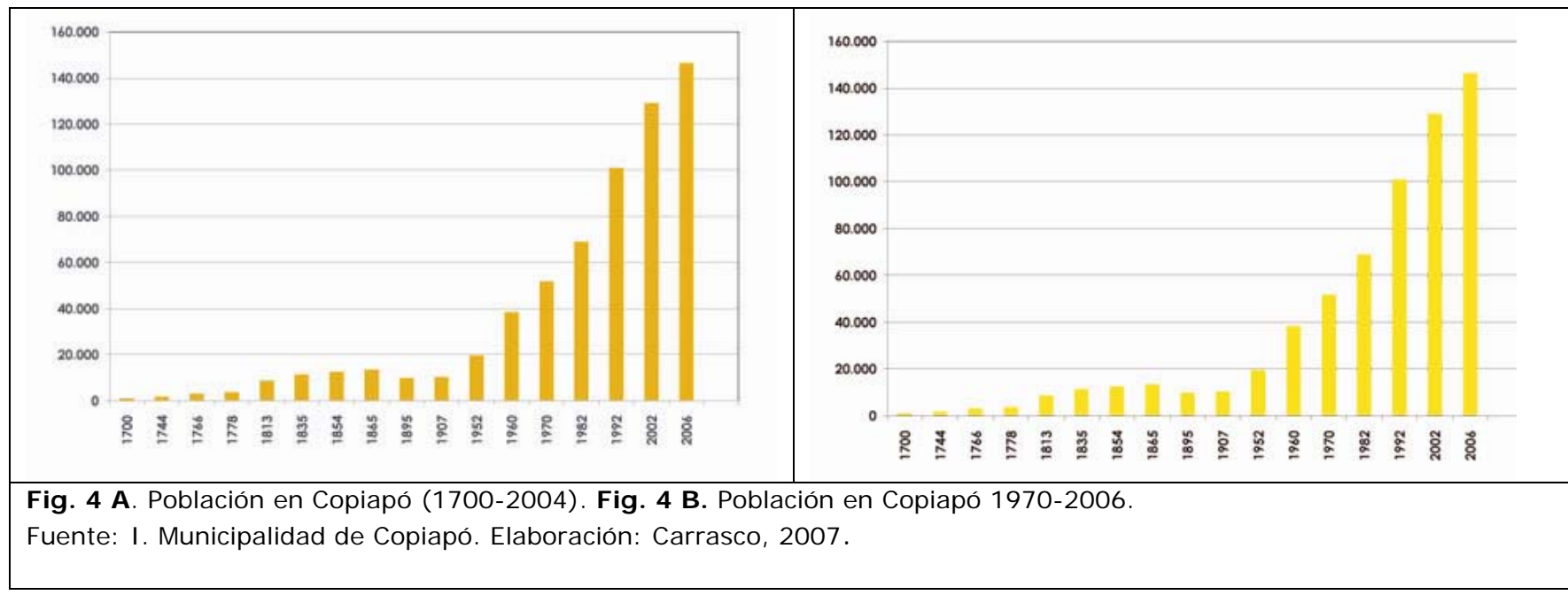

La evolución de la permisos de edificación, aprobados en Copiapó, indica un explosivo crecimiento en edificación que ha sufrido la ciudad en los últimos 30 años; a partir de 1976 se observa una curva ascendente que alcanza un peak en 1986 y un dramático descenso en 1990, que coincide con un cambio político importante, de un gobierno militar a un gobierno democrático. Sin embargo, esta contracción del sector construcción dura poco, pues vuelve a tomar una curva ascendente muy pronunciada. De hecho el modelo económico orientado a las exportaciones continua, pero en otro contexto administrativo político de gobierno.

En la Fig.5 se observan las curvas de permisos de edificación en relación a indicadores económicos tal como el Producto Interno Bruto PIB, comparando el sector minero con el agropecuario en la región de Atacama. La tasa de variación promedio del sector minero presenta un desfase de la curva respecto a la curva de los permisos de edificación. Emerge, en primer lugar, un incremento en los permisos de edificación que alcanza un peak a fines de los ochenta; en cambio, la tasa de variación del producto interno bruto derivado del sector minero, lo alcanza en 1990. Luego la curva baja y vuelve a alcanzar un nuevo peak en 1995 para, posteriormente, caer abruptamente hasta el 2002. En cambio, la curva que representa la tasa de variación del producto interno bruto agropecuario, prácticamente coincide con las tendencias de las curvas de los permisos de edificación, presentando en los mismos años un peak, en 1988, en 1995 y en 
1998. Lo anterior nos permite inferir que ocurren procesos concatenados entre el crecimiento del sector agropecuario y el crecimiento de la actividad edificatoria.

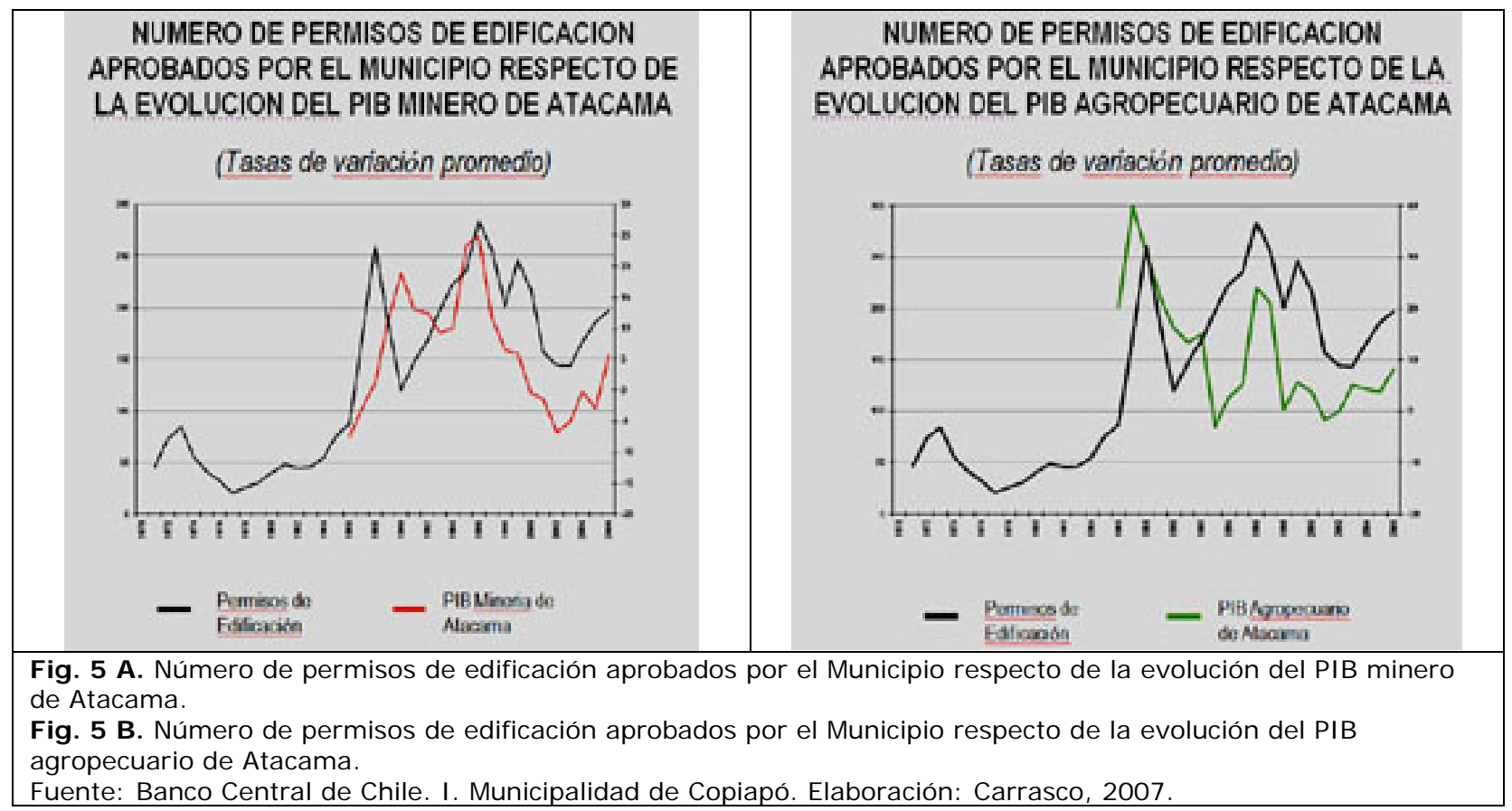

La actual estructura urbana de Copiapó, se caracteriza por su linealidad, emplazada de norponiente a sur-oriente a lo largo del valle transversal de Copiapó y delimitada por la hoya del río del mismo nombre, la ciudad de Copiapó, se desenvuelve naturalmente en uno de los sectores más amplios de la cuenca, a partir de la quebrada de Paipote.

Con un total de 4.400 Has. al interior del límite urbano comunal, su ocupación histórica se ha dado, en las áreas propicias como "el plan" al norte del río y en las laderas de poca pendiente de los cerros cercanos. Del mismo modo, y atendiendo a la capacidad local instalada de infraestructura vial y de servicios sanitarios, el área destinada a la edificación se ubica preferentemente al norte del río, en casi toda su extensión. Sin embargo, a inicios del siglo XXI cruza este umbral y se incorporan terrenos al sur del río, presentando en la actualidad, tres macro zonas bien delimitadas geográficamente como lo muestra la Fig.6. 


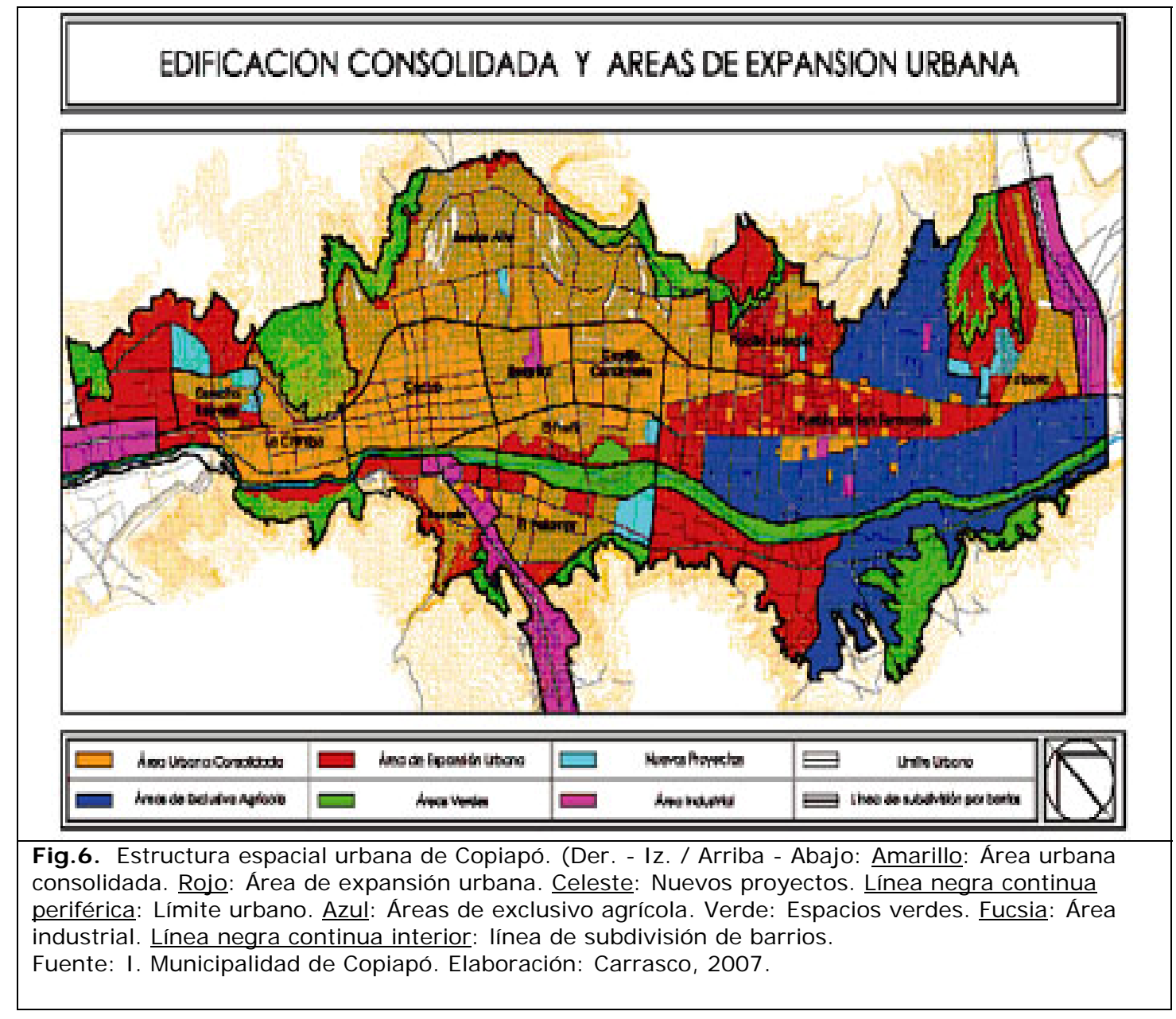

Los "sectores altos", están localizados en el frente norte de la ciudad, en las laderas de los cerros que conforman el valle; en este sector de la ciudad se ha concentrado cerca del $45,2 \%$ del total comunal de la población y un porcentaje similar de vivienda; la ocupación es fragmentada e incluye principalmente programas de vivienda social y vivienda de autoconstrucción.

Un segundo sector reconocible geográficamente está constituido por los terrenos ubicados al sur del río. Principalmente, es el "EI Palomar", en el borde sur del río, donde durante los últimos diez años la población se ha ido asentando con gran presencia modificando, así, los límites naturales de la estructura de la ciudad. Este barrio reúne cerca de un $9 \%$ del total comunal de población y vivienda, con un stock de construcción más reciente, lo que se explica por la concentración de nuevos programas de vivienda social, con inversiones en equipamientos, infraestructura, servicios y áreas verdes. El elemento común en ambos sectores es el ingreso, mayoritariamente bajo, y la disponibilidad de terrenos baratos, destacando como las áreas más densamente pobladas de la comuna.

Finalmente, aparece "el plan". La ocupación de esta tercera macro zona, ha sido en la parte central del valle, en una explanada con una pendiente de $0,75 \%$, en el sentido del río. Aquí podemos encontrar el centro histórico de la ciudad y sus extensiones naturales, que en conjunto, se explican como tres polos de desarrollo, ubicados de oriente a poniente, en cierta relación con el emplazamiento de las iglesias originales de Copiapó. Agrupando a una serie de barrios que se ordenan según la red vial de oriente a poniente: Paipote y San Fernando, Capilla Candelaria, hospital, Pretil, Centro Histórico, la Chimba y Cancha Rayada. Se trata del sector más antiguo y 
más valorado de la ciudad ya que presenta las mejores condiciones de habitabilidad, así como la mejor dotación de servicios y equipamiento de la ciudad.

La actividad industrial y de almacenaje al interior de la ciudad se hace presente de manera fragmentada. Esta actividad tiene preferencia por la conectividad que encuentran al borde de las carreteras, concentrándose preferentemente en Paipote, cercano al camino Internacional y de manera fragmentada en los accesos regionales a la ciudad, especialmente en la Ruta 5, en la zona del Palomar y la salida norte a Caldera.

Se puede observar una concentración de servicios, comercio y equipamiento en el centro histórico de la ciudad. Paralelamente, se observa la creación de nuevos polos de servicios asociados principalmente al comercio mayorista y retail; específicamente, supermercados y multitiendas, los cuales se localizan en el eje Van Buren. Los usos de suelo mencionados se encuentran cercanos a las grandes vías de la ciudad y a los barrios en que reside la población con mayores y también menores recursos, como El Palomar. Por otra parte, en la distribución del equipamiento urbano ocurre una situación similar.

Entre los problemas generados por la rápida extensión que ha experimentado la ciudad está la condición geográfica de desierto, la que representa un límite claro y no permite extenderse más allá sin cambiar drásticamente las condiciones de habitabilidad, afectando la calidad de vida de sus habitantes. En este crecimiento no se consideran los factores ambientales involucrados, se aprecia entonces merma en la condiciones bases originales y un déficit en los elementos conformadores de la estructura urbana, principalmente por el alto consumo de los escasos suelos agrícolas, para generación de vivienda, donde prácticamente no hay una compensación en espacios públicos, ni en áreas verdes asociados a la nueva población. Esto sin considerar la escasez de suelo para vivienda social, o el estado del recurso hídrico dada la actual condición de las reservas de agua en la cuenca, el escaso escurrimiento de aguas superficiales que dan sentido al río como elemento conformador de la ciudad, elementos claves para una planificación urbana futura.

4. Renovación de los usos de suelo y la arquitectura emergente en la ciudad de Copiapó. La dinámica de los cambios en los usos de suelo requiere de una interpretación desde la economía urbana, pues son las actividades productivas las que generan puestos de trabajo y esto ofrece oportunidades de empleo que atraen población al área de estudio. La población localizada a su vez demanda suelos y espacios por localizarse, vale decir un stock edificado. Si estos espacios existen dentro de la ciudad son ocupados por vivienda, servicios, y empresas, si no existen, se produce una presión por localizarse sea al interior de la ciudad mediante aumento de la densidad edificada, o una expansión hacia la periferia. Las empresas también demandan suelos, servicios e infraestructura para su localización en las ciudades en un contexto económico local expansivo, y no sólo consideran las relaciones funcionales sino también las restricciones impuestas por el stock físico a la localización tales como edificación, suelo y redes de transporte.

En la ciudad de Copiapó se observan ambos fenómenos, demanda de suelos y espacios edificados, para las viviendas, los servicios y las empresas, como consecuencia de la actividad productiva: exportación agrofrutícola del valle de Copiapó. Se constata en el período observado del 80 y 90 , un aumento de superficies de suelo y edificios para localizar estas actividades urbanas, vale decir la reacción de un mercado inmobiliario local. En la Fig. 7 se muestra la composición de usos de suelo en la ciudad de Copiapó. En la Fig. 8 se muestra la arquitectura emergente residencial y de oficinas, en la ciudad de Copiapó. 

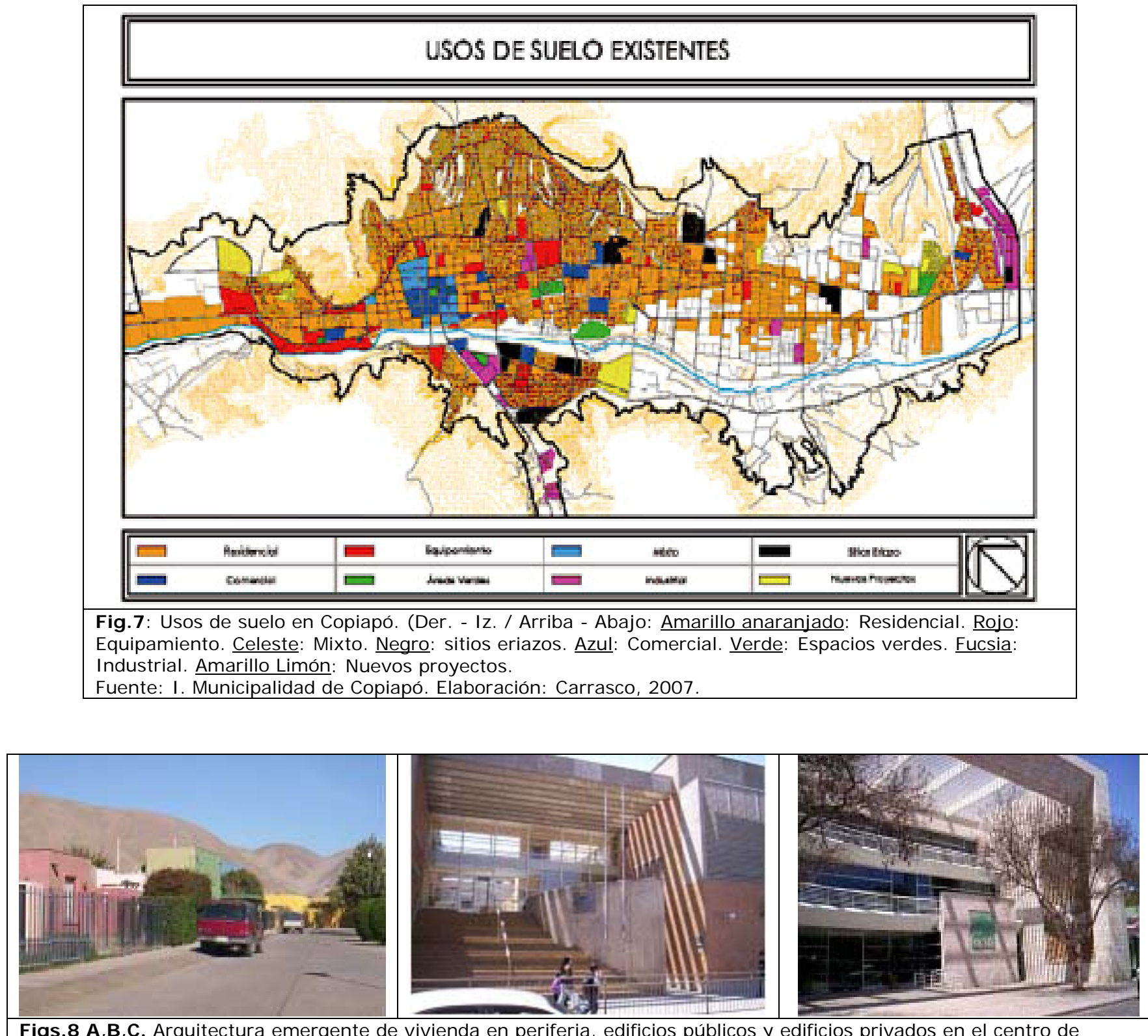

Figs.8 A,B,C. Arquitectura emergente de vivienda en periferia, edificios públicos y edificios privados en el centro de Copiapó. Fuente: terreno. Elaboración: Cárdenas, 2007.

La población atraída por la actividad productiva está compuesta por población flotante o estacional, la cual corresponde a temporeras (os), como también a la población residente: transportistas, técnicos y profesionales asesores, etc. Esta última emigra de otras regiones para asentarse, fijando su residencia en núcleos urbanos y principalmente en Copiapó, teniendo como fuente principal de empleo los servicios. Fig. 9. 
Fig.9.

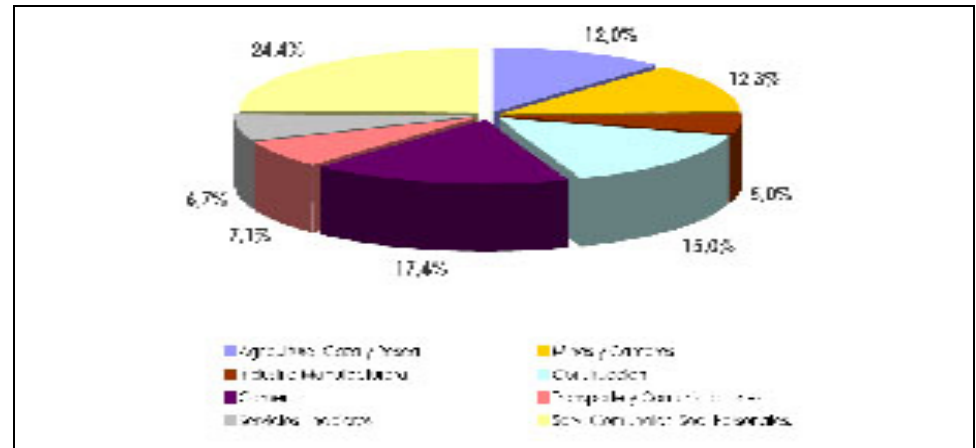

Fig. 9. Composición del empleo regional en Atacama.

Fuente: Encuestas de empleo INE. Elaboración: Carrasco, 2007.

Considerando como hipótesis que el proceso de globalización ha producido efectos en la estructura urbana de algunas ciudades chilenas de rango medio, vinculados al modelo exportador, tales como Copiapó, se procede a buscar una metodología que permita demostrar la hipótesis. Para ello se emplea, en primer lugar, los referentes conceptuales de Sassen, (Sassen, op. cit.), en relación con aquellos servicios que sostiene las actividades productivas de exportación y que ella acuña como los "los servicios de producción avanzada". Para ello el método de trabajo consistió en buscar los registros oficiales de actividades económicas en la comuna de Copiapó. Se contacta a la dirección de Rentas Municipales y se analizan los registros de las patentes municipales de la ciudad de Copiapó para dos períodos, el año 2000 y el año 2007, de acuerdo a la información disponible.

A partir de esta base de datos consistente en 6.270 patentes se identifican aquellos "servicios de producción avanzada" vinculantes al proceso exportador frutícola y se constatan mediante inspección visual en terreno aquellos casos inciertos. Luego se cuantifican y se compara la cantidad de los servicios registrados en el año 2000 y en el año 2007 a fin de conocer la evolución de ellos, según se muestra en la Fig.10. Los servicios identificados se desglosan en los siguientes: de publicidad, de contabilidad y auditorias, financieros excluidos los accionistas, financieras, comunicaciones, compañías de seguros, bancos, asesorías tributarias, asesorías económicas, financieras y tributarias, agentes de seguros, agentes de aduanas, asesorías en comercio exterior.

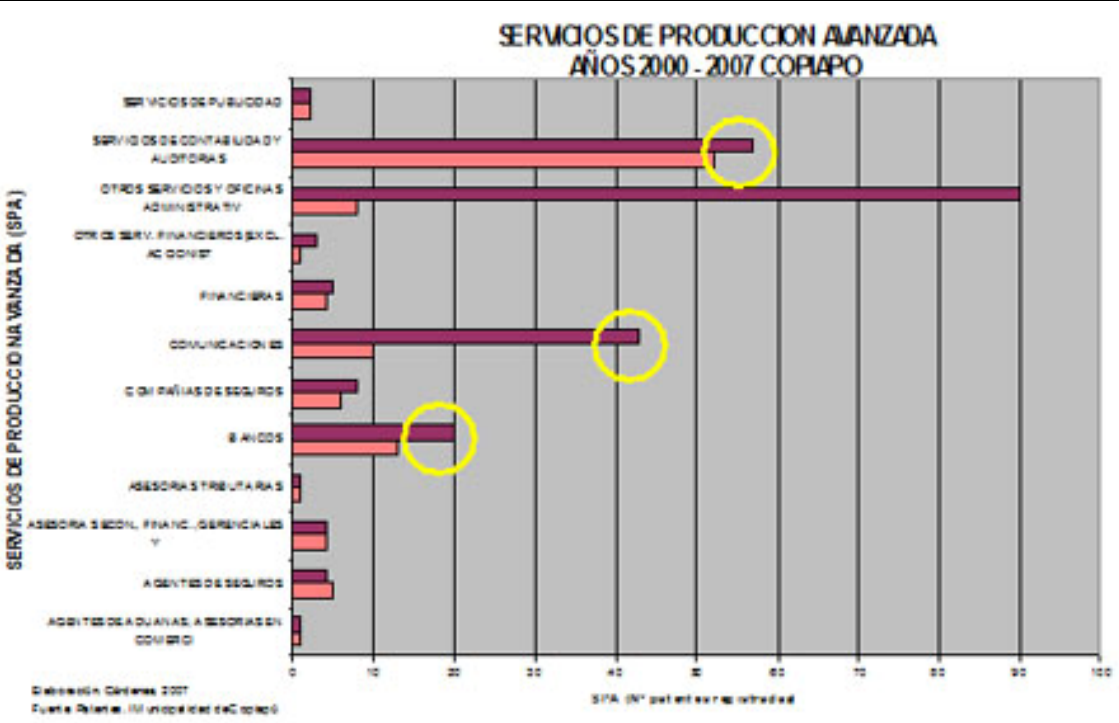

Fig. 10. Servicios de Producción avanzada en Copiapó.

Fuente: I. Municipalidad de Copiapó. Elaboración: Cárdenas, 2007. 
Se observa en este conjunto tres tipos de servicios que presentan un crecimiento significativo: los bancos, comunicaciones, y contabilidad y auditoría. En un segundo orden de magnitud figuran las compañías de seguros, las financieras y otros servicios financieros, excluidos las acciones. Los servicios que no experimentan crecimiento sino que se mantienen en este período son publicidad, asesorías tributarias y agentes de aduanas y comercio exterior. La actividad que experimenta un leve decrecimiento es el servicio agente de seguros.

En breve, se observa una diversidad de servicios asociados a la actividad exportadora y un incremento de ellos en el orden de magnitud dentro del período observado. Es importante mencionar que en la fase inicial del proceso, a fines de los 70, parte de estos servicios se localizaban en otra ciudad de mayor rango y tamaño, ubicada aproximadamente a unos $300 \mathrm{kms}$, La Serena. El crecimiento sostenido de la actividad exportadora frutícola de la uva de mesa y su correspondiente demanda creciente de servicios asociados al proceso, determinó su localización en la ciudad de Copiapó.

En segundo lugar, se considera como otro referente conceptual de globalización a De Mattos, quien también ha estudiado in extenso efectos del fenómeno sobre las ciudades y el territorio, en particular la metrópolis, (De Mattos, 1999). Se emplea la noción de "artefactos de la globalización", como los elementos de soporte físico al proceso de globalización, entre los cuales se encuentran la construcción de obras de infraestructura vial y comunicaciones, arquitectura hotelera de alto nivel, megacentros de ocio y comercio, residencias en condominios, etc. Se realiza una re-interpretación para el sistema urbano-territorial del valle de Copiapó, el cual no corresponde a una metrópolis, sin embargo, sí se manifiestan hitos en la estructura física coincidentes con los observados en las metrópolis, pero a una escala menor.

La metodología consistió principalmente en trabajo de campo, partiendo por un recorrido del valle en toda su extensión, desde el tranque Lautaro ubicado a $1.158 \mathrm{msnm}$ (metros sobre el nivel del mar), recorriendo el valle y los parronales a lo largo del eje central de la cuenca hidrográfica, cruzando por la ciudad cabecera, Copiapó, y terminando en el puerto de Caldera, en la costa. La transformación del paisaje natural, con un fondo de valle seco, de color tierra y cerros con visos de color morado y ocre contrasta con el verde de los parronales a lo largo de la ruta principal. Otro elemento característico del paisaje es la irrupción de arquitectura industrial de almacenamiento y procesamiento de la mercadería: la uva de exportación. Esta "arquitectura del packing", aparece sistemáticamente a lo largo del valle con una volumetría predominante horizontal. Fig.11. Algunas de las empresas frutícolas y agroexportadoras localizadas en territorio interurbano son: Del Curto, Del Monte, Norfrut, Unifruti, Aconex, Río Blanco.

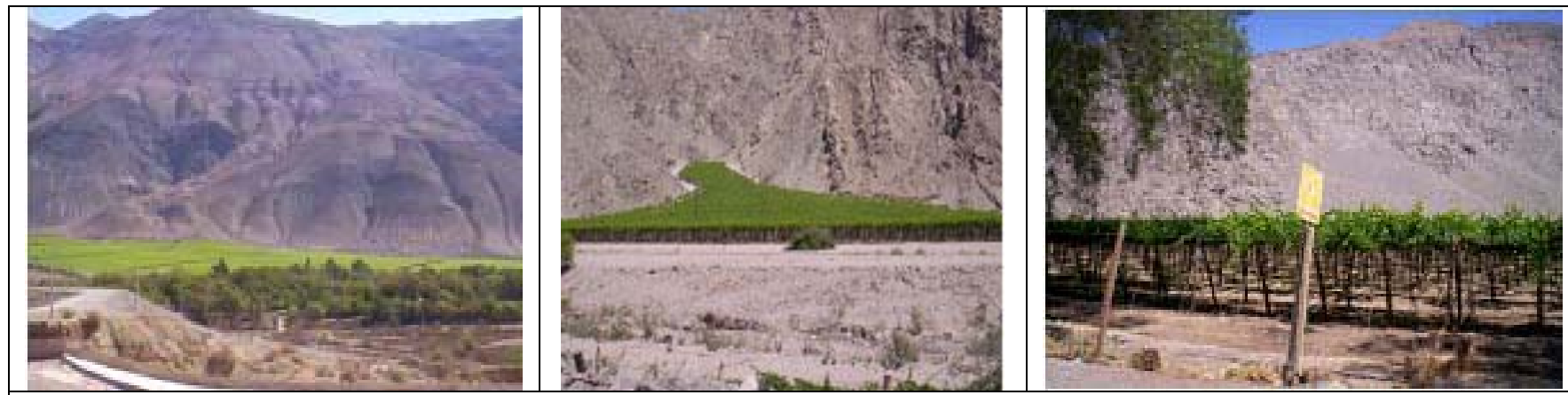

Figs. 11 A, B y C: Parronales en el semiárido del valle de Copiapó.

Fuente: terreno. Elaboración: Cárdenas, 2007.

Se identificaron "artefactos de globalización" vinculantes al proceso exportador agrofrutícola, se reverenciaron geográficamente mediante un equipo GPS y se confeccionó una cartografía para 
estos fines. En la Fig. 12 se han localizado aquellos artefactos emplazados a lo largo del territorio y en la Fig. 13 se muestran algunas imágenes:

- Un nuevo aeropuerto llamado “Desierto de Atacama” (2004) que reemplaza al antiguo aeródromo de Chamonate.

- Una "vía de la fruta" que corresponde a un tramo de vía que nace de la ruta Norte Sur y conecta directamente con el puerto de Caldera, para facilitar un embarque rápido y directo.

- Áreas residenciales en la periferia de ingresos alto y medio, cercanas al antiguo Chamonate y cercanas al conjunto residencial Candelaria, sector exclusivo de muy altos ingresos asociados a la actividad minera exclusivamente; equipamiento de educación básica y secundaria privada; áreas residenciales de ingresos medios y bajos situados en El Palomar y cercano a Paipote.

- Hotel cuatro estrellas, El Chagall, situado en centro de la ciudad de Copiapó a cincuenta metros de la plaza central.

- Los megacentros comerciales tales como Jumbo, Easy, Deco, situados en el borde de la ciudad y contiguo a la vía interurbana Av. Copayapu.

- Equipamiento del ocio y recreación asociado al capital situado en un área degradada de la ciudad de Copiapó, el nuevo Casino de Juegos de azar.

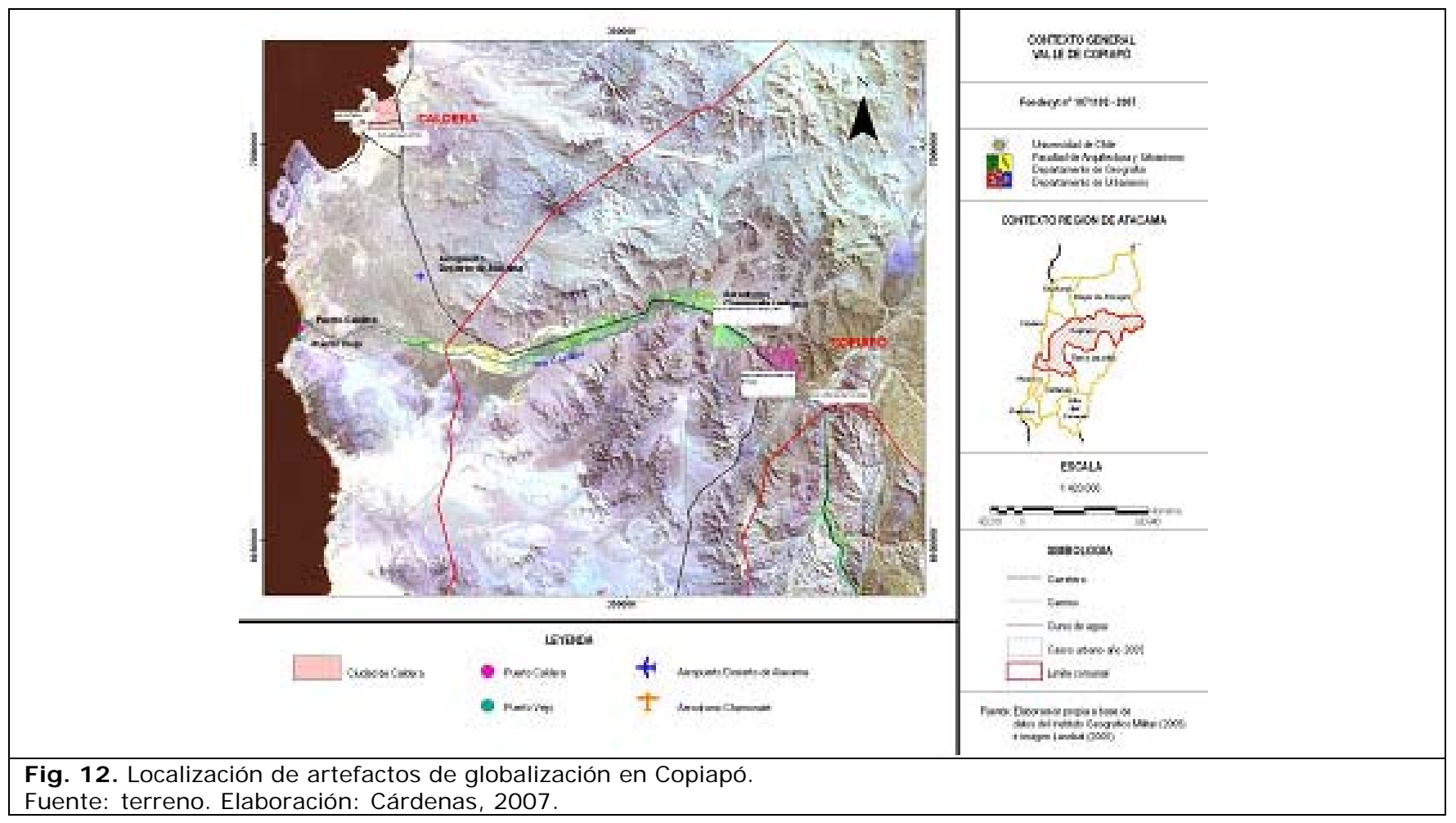




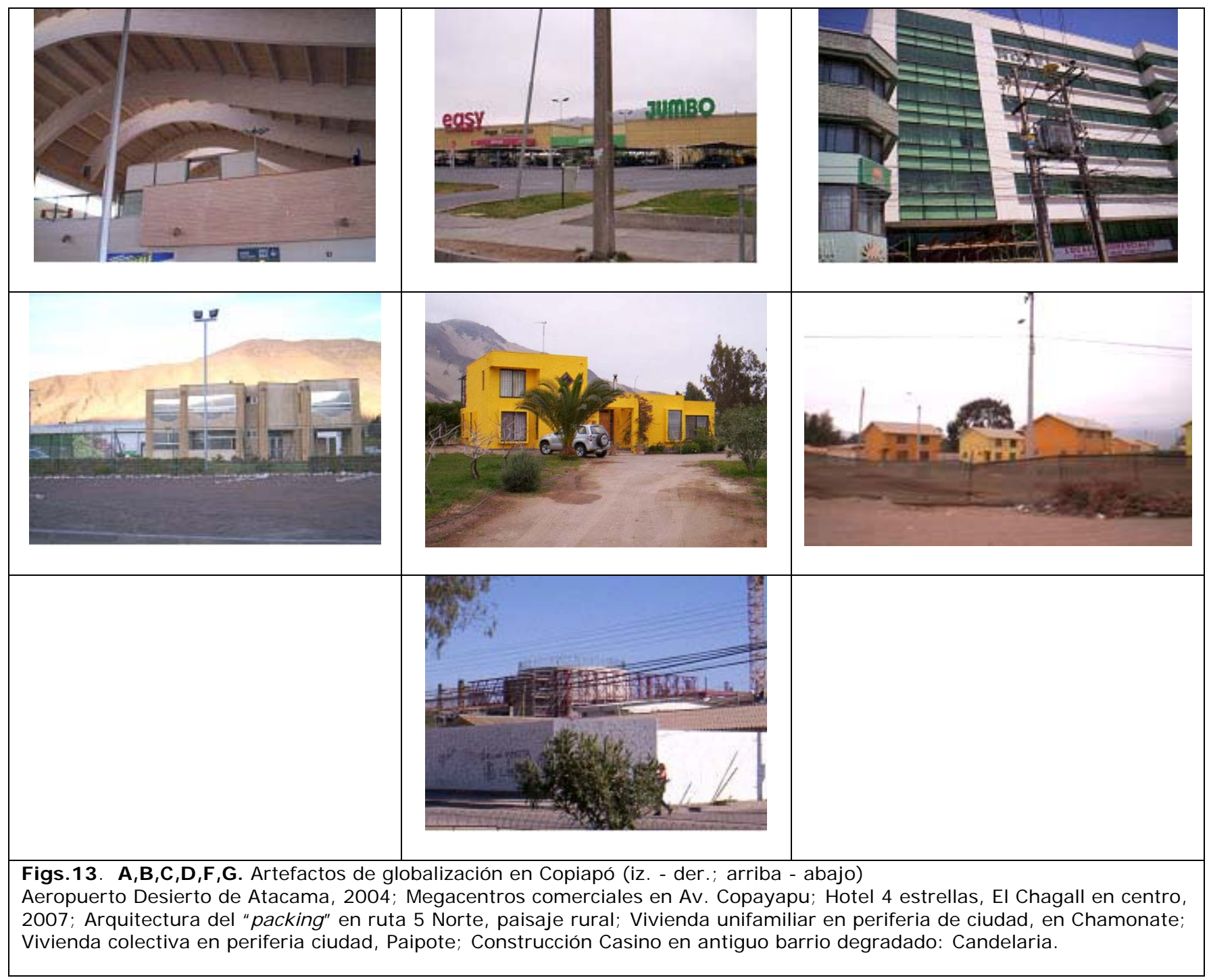

\section{Reestructuración del espacio urbano y territorial}

Los estudios presentados permitan afirmar que ocurrió una transformación del espacio urbano y territorial derivado de la aplicación de un modelo exportador en base a recursos naturales y las ventajas comparativas de la región. Se observa tendencias de crecimiento demográfico y de permisos de edificación aprobados por el municipio de Copiapó que son coincidentes con la evolución del Producto Interno Bruto PIB agropecuario de Atacama. En efecto, en los años 1987 1988 la Fig. 4 muestra un peak de población que supera los 250.000 habitantes y coincide con el mayor peak del PIB agropecuario ocurrido en esos mismos años según muestra la Fig. 5. Luego experimenta una baja en ambos gráficos al llegar a los noventa, período eleccionario y de cambio de gobierno, momento de inflexión de la curva, para posteriormente comenzar a ascender gradualmente hasta llegar a un nuevo peak a mediados de los noventa con más de 300.000 habitantes y un elevada tasa de variación del PIB agropecuario.

Otro factor desencadenado por la actividad económica frutícola de exportación, es la creación de espacios edificados; el cual se constata a través de la variable permisos de edificación. La Fig. 5 indica tendencias similares entre los permisos de edificación aprobados por el municipio de Copiapó y la curva de la evolución del PIB agropecuario de Atacama. En resumen, la actividad básica crea puestos de trabajo, los cuales generan empleo y este atrae a población residente. La población requiere de otros servicios asociados tales como vivienda, alimentación, educación, 
salud, etc., los cuales requieren de espacios construidos para sostener estas actividades complementarias. Por otro lado, a medida que crece la actividad básica requiere de otros servicios prestados por pequeñas empresas que necesitan de espacios edificados y así se activa el mercado inmobiliario de oficinas y viviendas.

La dinámica inmobiliaria experimentada por el sector privado como por el sector público se refleja en edificios con destino a los servicios de producción avanzada como a los servicios públicos localizados en la trama urbana del damero central de Copiapó. Este fenómeno induce a procesos de renovación urbana, en particular aquellas áreas más degradadas, por la diversidad de actividades que vitalizan el uso del espacio público como también nuevas construcciones que reemplazan a antiguas deterioradas con el tiempo.

Desde una perspectiva de globalización se constata la existencia de los llamados "servicios de producción avanzada", los cuales se incrementan y además se diversifican en el período observado, 2000 - 2007, en particular, los servicios bancarios y de telecomunicaciones, básicos para una economía globalizada. Por otro lado, los llamados "artefactos de la globalización" también tienen presencia en el espacio urbano y a lo largo del territorio regional. En el primer caso, cercano al centro de la ciudad, en el área de influencia de la plaza principal, en el segundo caso, localizándose a lo largo y en los bordes del eje estructurante del valle de Copiapó: la Avenida Copayapu.

Se concluye que el modelo de política económica abierta a las exportaciones, en este caso frutícola, ha generado no sólo un crecimiento económico sino que también un desarrollo urbano a lo largo del eje de conectividad de los centros poblados y principalmente en el centro de mayor jerarquía del sistema urbano. Esto queda evidenciado a través de la generación de empleo y una expansión en los suelos, espacios edificados e infraestructura de transporte y comunicaciones. En Copiapó el crecimiento físico se observa en dos modalidades: por extensión y por densificación. El crecimiento por extensión ha cruzado la barrera orográfica que constituía el río Copiapó y se ha extendido hacia el interior del valle como también hacia la Costa con dotaciones de equipamiento para la actividad residencial.

La atracción que ejerce el empleo, se refleja en el aumento de la población residente en los distintos niveles socioeconómicos y ofertas de viviendas con valores entre $800 \mathrm{UF} / \mathrm{m} 2$ y las 4.000 $\mathrm{UF} / \mathrm{m} 2$. Cabe mencionar que hay sectores residenciales con valores aun muy superiores de la vivienda, como es el sector de La Candelaria, pero que responden a residentes vinculados con la actividad minera y se han excluido en este análisis para evitar distorsión en la interpretación de los antecedentes. La actividad residencial y de pequeñas empresas de servicios atrae inversiones para la ciudad produciendo nuevos necesidades arquitectónicas y urbanísticas. Estas constituyen aun un desafío pues, según se observa en terreno, la velocidad de crecimiento no siempre va acorde a la calidad de sus espacios públicos.

En suma, la transformación consistió fundamentalmente en un crecimiento físico, demográfico, inmobiliario y de actividades económicas de la ciudad de Copiapó. En forma particular, ocurre la emergencia de la "arquitectura del packing" al borde de la ruta vial estructurante y en suelos agrícolas. Estos últimos elementos estructurantes del territorio se localizan principalmente fuera del radio urbano de la ciudad de Copiapó, en el territorio comprendido entre la ciudad y la costa, donde se ubica el puerto de Caldera; y entre la ciudad y el interior del valle, lugar donde se emplaza el conjunto de centros poblados menores y villorrios, tales como Tierra Amarilla, Los Loros, etc. Otra perspectiva de análisis, como proyección del presente artículo, podría ser la localización de la estructura social emergente, en función de los atributos del lugar, (Cárdenas, 2000) o la nueva morfología arquitectónica de la estructura urbana.

Nota: Este artículo corresponde a un resultado parcial de un proyecto de investigación realizado gracias al financiamiento de CONICYT FONDECYT №1071102 (2007-2009) IMPACTO DE LA GLOBALIZACION EN EL SISTEMA URBANO CHILENO: ESPECIALIZACION PRODUCTIVA, CAMBIOS SOCIALES Y REESTRUCTURACION ESPECIAL. ANALISIS DE CASOS. Investigador Responsable: Dr. Geógrafo Jorge Ortiz Véliz; CoInvestigadoras: Geógrafa Carmen Paz Castro Correa y Arquitecta Luz Alicia Cárdenas Jirón. Se agradece la colaboración de la tesista en Geografía, Lindsay Fritz, quien realizó la cartografía regional en este artículo. 


\section{Referencias}

BANCO CENTRAL DE CHILE. Boletín Mensual, Vol. 81, N966, Santiago de Chile, Banco Central de Chile, 2008, 321pags., ISSN 0716-2367.

BANCO CENTRAL DE CHILE. Boletín Mensual, Vol. 73, N863, Santiago de Chile, Banco Central de Chile, 2000, 3705-3995 pags., ISSN 0716-2367.

BANCO CENTRAL DE CHILE. Indice de Exportación 1986 - 1999, Santiago de Chile, Banco Central de Chile, 2000, 311pags., ISSN 0717 - 5876.

CARRASCO MILLA, Pablo, Crecimiento Urbano de Copiapó. Causales, patrones y perspectiva. Seminario de Investigación, Santiago de Chile, Facultad de Arquitectura y Urbanismo. Universidad de Chile, 2007, 134 págs.

CÁRDENAS JIRÓN, Luz Alicia; FRITZ, Lindsay, Cambios territoriales y funcionales en una ciudad de base económica lateral, el caso de Copiapó. Ponencia en Coloquio: Del país urbano al país metropolitano. Campus San Joaquín. Pontificia Universidad Católica de Chile. 4-6 Diciembre, 2007, Santiago.

CHAPIN, F. Suart, Urban land use planning, Urbana, University of Illinois Press, 1965, 498 págs.

DIE Atlas de Chile y el mundo, Santiago de Chile, Copesa Editorial, 2007, 141 págs., ISBN 978956-15-1349-5.

SECRETARÍA COMUNAL DE PLANIFICACIÓN, Plan de Desarrollo Comunal, Copiapó, Ilustre Municipalidad de Copiapó, 2002, 216 págs.

DE CASTRO, Sergio, El ladrillo: Bases de la política económica del gobierno militar chileno, Santiago de Chile, Editorial Centro de Estudios Públicos, 1992, 193 págs., ISBN 956-7015-07-4.

DE MATTOS, Carlos, "Santiago de Chile: globalización y expansión metropolitana: lo que existía sigue existiendo", en revista EURE, Vol. XXV, №76, Santiago de Chile, editada por Pontificia Universidad Católica, 1999. pp. 29-56, ISSN 0250-7161.

FIGUEROA, Eugenio; DONOSO, G., LAGOS, G., ALVAREZ, R., MUÑOZ. J. "Sustentabilidad ambiental del sector exportador chileno", en Sustentabilidad ambiental del crecimiento económico chileno. Santiago de Chile, editado por Centro de Análisis de Políticas Públicas, Universidad de Chile, 1996, pp. 47-86 ISBN 956-19-0211-7.

FIGUEROA, Eugenio, "Sector Silvoagropecuario", en: Comentarios sobre la situación económica. Santiago de Chile, editada por Departamento de Economía, Universidad de Chile, 1993, pp169199. ISSN 0176 - 4025.

GWYNNE, Robert, "Globalisation: commodity chains and fruit exporting regions in Chile", en Tijdschrift voor Economische en Sociale Geografie ,Vol. 90, №2, Oxford, Blackwell Publishing Limited, 1999, pp 211-225. ISSN 0040-747X.

GWYNNE, Robert, "Social change and agroexportation in semid-arid regions of Chile", en Regadío y desarrollo en las regiones semiáridas latinoamericanas. LUZON, J osé Luis; LINCK, Thierry. (Ed.) Barcelona, editada por Universitat de Barcelona, 1997, pp91-96 ISBN 84-605-7073-8.

GWYNNE, Robert, "Non traditional Export Growth and Economic Development. The Chilean Forestry Sector since 1974". Bulletin of Latin American Research, Vol. 12, №2, Oxford, Blackwell Publishing Limited, 1993, pp147-169. ISSN 0261-3050. 
GWYNNE, Robert; KAY,Cristóbal, "Agrarian change and the democratic transition in Chile: an introduction", en Bulletin of Latin American Research, Vol. 16, №1, Oxford, Blackwell Publishing Limited, 1997, pp 3-10. ISSN 0261-3050.

CÁRDENAS JIRÓN, Luz Alicia, Atributos urbanísticos de la localización residencial en el Gran Santiago. Ultimo cuarto de siglo. Santiago de Chile, editado por Facultad de Arquitectura y Urbanismo, Universidad de Chile, 2000, 98 págs., ISBN 956-19-0502-7.

LUZON, José Luis, "Regadío y desarrollo en el norte chico y en el valle de San Francisco", en Regadío y desarrollo en las regiones semiáridas latinoamericanas. LUZON, José Luis; LINCK, Thierry. (Ed.) Barcelona, editada por Universitat de Barcelona, 1997, pp 91-96 ISBN 84-6057073-8.

SASSEN, Saskia, The Global city. New York, London, Tokio. Oxford, published by Princeton University Press, 1991, 397 págs. ISBN 0-691-07866-1.

SASSEN, Sassen, "Localizando ciudades en circuitos globales", en EURE, Vol. XXIX, N88, Santiago de Chile, editada por Pontificia Universidad Católica, 2003, pp. 5-27 ISSN 0250-7161.

SUNKEL, Osvaldo. (Ed.) Sustentabilidad ambiental del crecimiento económico chileno, Santiago de Chile, editado por Centro de Análisis de Políticas Públicas, Universidad de Chile, 1996, 380 págs. ISBN 956-19-0211-7.

TALLON, Andrew, “Bristol”, en Cities, Vol. 24, №1, Oxford, Elsevier Science, 2006, pp74-88 ISSN 0264-2751.

http://www.copiapo.cl 